\title{
FACTORS 7.0: Curadoria e Estratégia Expositiva Online
}

\section{$\star$}

Nara Cristina Santos possui Pós-doutorado em Artes Visuais/UFRJ. Doutora em Artes Visuais/UFRGS com estágio na Paris VIII/França. Professora do DART/ UFSM desde 1993, atua na Graduação e Pós-Graduação das Artes Visuais/PPGART. Pesquisadora em História, Teoria, Crítica e Curadoria, com projetos transdisciplinares em Arte-Ciência-Tecnologia. Coordena o LABART www.ufsm. br/labart e lidera o grupo de pesquisa Arte e Tecnologia/CNPq. Organizadora e curadora do Festival Arte Ciência e Tecnologia/FACTORS. Tem convênios, projetos e publicações no Brasil e Exterior. Consultora da CAPES para área de Artes. Membro do Comitê Brasileiro de História da Arte (CBHA) e da Associação Nacional de Pesquisadores em Artes Plásticas (ANPAP), que presidiu no biênio 2015-2016.

<naracris.sma@gmail.com> ORCID: 0000-0003-4968-2738
Resumo O Festival de Arte, Ciência e Tecnologia atualiza a proposta curatorial e o projeto expográfico para a sétima edição, desta vez online. Diante da pandemia provocada pela Covid-19, as exposições artísticas estão sendo adaptadas ou mesmo inovadas em diferentes programas, aplicativos e plataformas para disponibilização na rede. No caso de obras de Arte e Tecnologia digital há um elemento complicador, a interação. Diante das limitações da mostra de obras interativas in loco neste ano, propõe-se pensar o distanciamento espaço-temporal como estratégia expositiva online. Tanto para discutir e projetar uma expografia que atenda as especificidades do FACTORS e as demandas das redes, quanto para questionar e propor modos de exibição do Festival, redimensionado ao público como um acontecimento, mais instigador e complexo no âmbito da cultura.

Palavras chave Arte contemporânea, Arte-ciência-tecnologia, Curadoria, Expografia online. 


\section{FACTORS 7.0: Curatorship and Online Exhibition Strategy}

Abstract The Festival of Art, Science and Technology updates its curatorship and its exhibition project for the seventh edition, this time online. In view of the pandemic caused by Covid-19, artistic exhibitions are being adapted or even innovated in different programs, applications and platforms to be made available on network. In the case of works of art and digital technology there is a complicating element, interaction. In view of the limitations of the exhibition of interactive works in loco this year, it is proposed to think of the space-time distance as an online exhibition strategy. Both to discuss and design an exhibition that meets the specifics of FACTORS and the demands of the networks, as well as to question and propose ways of showing the Festival, resized to the public as an event, more instigating and complex in the context of culture.

Keywords Contemporary art, Art-science-technology, Curatorship, Online exhibition.

\section{FACTORS 7.0: Curaduría y Estrategia de Exhibición Online}

Resumen El Festival de Arte, Ciencia y Tecnología actualiza la propuesta de curaduría y el proyecto expositivo para la séptima edición, esta vez online. Ante la pandemia provocada por la Covid-19, las exposiciones artísticas se están adaptando o incluso innovando en diferentes programas, aplicaciones y plataformas para estar disponibles en rede. En el caso de las obras de arte y tecnología digital, existe un elemento de complicación, la interacción. Ante las limitaciones de la exhibición de obras interactivas in loco en ese año, se propone pensar en la distancia espacio-tiempo como una estrategia de exhibición online. Tanto para discutir y diseñar una exposición que responda a la especificidad de FACTORS y las demandas de las redes, como para cuestionar y proponer formas de mostrar el Festival, redimensionado al público como un evento, más instigador y complejo en el contexto de la cultura.

Palabras clave Arte contemporáneo, Arte-ciencia-tecnología, Curaduría, Exhibición online. 


\section{Introdução}

Esse artigo trata de um relato da curadoria e expografia do FACTORS 7.0, que aconteceu de 18 a 28 de agosto, no contexto da pandemia em 2020. O Festival Arte Ciência e Tecnologia acontece anualmente, como resultado das atividades de ensino, pesquisa e extensão do grupo Arte e Tecnologia CNPq e LABART ${ }^{1}$. O Festival tem como objetivo promover, fortalecer e divulgar a produção na área através da exposição de obras e projetos, de artistas nacionais e internacionais com pesquisas consolidadas ou emergentes, que investigam diferentes linguagens, teorias e tendências, e colaboram para pensar e questionar o campo da arte contemporânea.

No FACTORS, o argumento curatorial tem como desafio uma concepção transdisciplinar a partir da qual se propõe um conceito que perpasse e problematize questões em torno da arte-ciência-tecnologia, a cada exposição. Por exemplo, neste ano, água e sustentabilidade. A curadoria é compartilhada entre duas pesquisadoras, uma do programa de Pós-Graduação em Artes Visuais da UFSM/Brasil e outra do Mestrado em Estética das Artes Eletrônicas da UNTREF/Argentina, desde a quarta edição. As curadoras selecionam artistas e obras, discutem questões emergentes de cada conceito da mostra anual, assim como propõe soluções para a exposição, tanto teórico-críticas, quanto prático-expográficas. O evento conta com apoio curatorial, de expografia e mediação, dos orientandos do LABART.

Conforme Paul (2008, p.38-43), os modelos de curadoria de novas mídias estão relacionados aos aspectos práticos e técnicos do trabalho de um curador, e são elas: o modelo interativo, o modelo modular, o modelo distributivo. Quando entendidos no amplo campo da Arte e Tecnologia, estes modelos podem estar presentes de modo geral em uma ou outra curadoria de eventos na área e, de modo particular, em relação a alguns artistas e obras. Mas há outros aspectos que surgem em relação à curadoria em arte-ciência-tecnologia naquilo que diz respeito ao vivo e ao natural, a natureza e a sustentabilidade, por exemplo, que demandam ampliar o estudo destes modelos ou mesmo desconsiderá-los, neste caso.

Para tratar da experiência vivenciada na atual edição do Festival, este artigo se divide em duas partes: na primeira, apresenta o projeto curatorial adaptado para essa sétima edição online, mantido o argumento curatorial transdisciplinar e os conceitos de água e sustentabilidade. $O$ foco atende a Agenda 2030 da ONU para políticas sustentáveis: 6 - Água potável e saneamento e o 14 - Vida na água. São selecionados artistas brasileiros e argentinos para os quais a concepção de água, nos seus trabalhos, não é apenas uma temática da obra, mas um elemento instigador na produção artística, assim como um conceito problematizador em torno da sustentabilidade e do meio ambiente.

Na segunda parte, discute-se a estratégia expositiva diante do isolamento imposto pela pandemia, considerando as especificidades de um Festival com obras de Arte, Ciência e Tecnologia. Parte-se dos estudos e versões iniciais do projeto expográfico in loco, até os resultados de uma proposta 
de expografia online, para atender as demandas de redes sociais como Instagram e Facebook, e ainda o Youtube. Considerando que o Festival exibe sempre obras tecnológicas, participativas, interativas e até imersivas, a adaptação a um espaço online compromete a interação do público com as obras. Neste ano, portanto, prioriza-se a exibição de obras em videoarte e de vídeo documento como alternativa possível. A proposta, como estratégia expositiva online, elaborada no curso de poucos meses, visa amenizar o distanciamento espaço-temporal para exibir o Festival nas três plataformas. $\mathrm{E}$ a mediação torna-se uma aliada nessa versão online para aproximação do público em rede, adequada ao projeto curatorial e expográfico.

\title{
Curadoria do FACTORS 7.0
}

\begin{abstract}
A curadoria na arte contemporânea se tornou amplamente reconhecida como uma profissão significativa, presa nos impulsos centrais da vida contemporânea, mas também capaz de oferecer interpretações surpreendentemente originais das complexidades e contradições de nossa contemporaneidade. (SMITH, 2015, p. 15)
\end{abstract}

A curadoria do Festival fundamenta-se na concepção transdisciplinar, entendida no seu diálogo e reconciliação com a arte, como 'além do campo, fora do campo, outro campo'. Pressupõe disciplinas que cooperam entre si, além e através delas mesmas, para um projeto comum que gera unidade, ainda que complexa, no resultado. Portanto, compreende-se a prática curatorial transdisciplinar não apenas como um modo de organizar o conhecimento a partir de diferentes disciplinas para constituir um pensamento sistêmico, mas também como um modo de se deixar atravessar, na produção em arte-ciência-tecnologia, por uma ação complexa.

O projeto curatorial de cada edição é elaborado em conjunto, a partir de um argumento-conceitual transdisciplinar, e iniciado nos meses de outubro e novembro do ano anterior ao evento. A proposta das curadoras, baseada nos conceitos definidos para o ano, com seleção de artistas e obras, é apresentada e discutida no LABART. Depois de convidados e confirmados os artistas, a curadoria dá início a três atividades: uma em torno do texto e discurso curatorial, cuja atuação acontece previamente à exposição; outra voltada para a expografia e projeto expográfico, cuja ação ocorre antes e durante a organização, montagem e exibição do Festival; e, a terceira, da mediação, que acompanha as atividades anteriores para atuar durante o Festival. Depois do evento é publicado o catálogo do Festival, através de e-book pela Ed. do PPGART/UFSM. ${ }^{2}$

Para a sétima edição do FACTORS, com a pandemia o distanciamento social, as atividades precisam ser reorganizadas. A curadoria mantém o argumento com os conceitos de água e sustentabilidade, a seleção inicial 
dos artistas, mas necessita rever a escolha das obras, para adaptar-se, assim como a expografia e a mediação. Afinal, as edições anteriores, em sua maioria na sala de exposições Cláudio Carriconde do CAL/UFSM, tem agora em 2020 , a alternativa de outro espaço-temporal, o do acontecimento online, com base nas redes sociais do LABART, no Instagram, mas também no Facebook e no canal no Youtube. ${ }^{3}$

Pensar o Festival a partir do acontecimento online, fez esta autora encontrar em Slavoj Zizek um apoio conceitual para tempos estranhos, como os que estamos todos vivendo. Em uma primeira definição de "acontecimento", ele trata antes de uma característica básica do conceito: "o surgimento de algo novo que solapa qualquer esquema estável” (2017, p. 11). Portanto, poderia se compreender o acontecimento como "uma guinada em nossa relação com a realidade" (2017, p. 35). Para Zizek, "Num acontecimento, as coisas não apenas mudam: o que muda é o próprio parâmetro pelo qual avaliamos os fatos da mudança, ou seja, um ponto de inflexão muda todo o campo no qual os fatos aparecem" (2017, p. 165).

Nessa aproximação rápida do conceito de Zizek, não há pretensão de relacioná-lo diretamente com a ideia do acontecimento online nesta curadoria, mas sim entender no conceito de "acontecimento", qual seria o ponto de inflexão que muda todo campo, o que poderia incluir o campo da arte e o da cultura hoje. Um estudo para outro momento. 


\section{FACTORS 7.0}

O que pensar sobre a água, um recurso natural que pode acabar? Pelo menos do modo como a desejamos, abundante e limpa, para manutenção da vida. Essa é uma questão urgente de sustentabilidade. A água não está limitada a países e suas fronteiras políticas. Só no Brasil, há o compartilhamento de muitos rios, bacias e os importantes aquíferos, o Guarani e o Amazonas, com outros países. A preservação da água, portanto, deve ser realizada por meio de ações sustentáveis, pensadas além de fronteiras, de instâncias pública e privada, ou da ideia de nação e indivíduo. Deve prever uma ação conjunta responsável aliada a uma atuação particular consciente e ética, na e para com a natureza. Na Agenda 2030 da ONU para políticas sustentáveis, defende-se no Festival os objetivos 4-Educação de qualidade e o 12-Consumo e produção responsáveis. Para 2020 também o 6-Água potável e saneamento e o 14-Vida na água. Os artistas convidados para o FACTORS 7.0 apresentam obras e projetos, sejam vídeos, fotografias, objetos e performances, que tratam do tema água e sustentabilidade como conceitos específicos de um argumento curatorial fundado na transdisciplinaridade.“ (...) Artigo 5: A visão transdisciplinar é deliberadamente aberta na medida em que ela ultrapassa o domínio das ciências exatas pelo seu diálogo e a sua reconciliação não somente com as ciências humanas mas também com a arte, a literatura, a poesia e a experiência interior". (Carta da Transdisciplinaridade, de Basarab Nicolescu, Edgar Morin, e Lima de Freitas. https://fr.scribd.com/document/155577806/ Carta-de-Transdisciplinaridade) É nesta relação transdisciplinar entre arte, ciência e tecnologia, que cada um dos nove artistas compartilha a água como elemento problematizador de uma prática visual, sonora, tátil, audiovisual, digital, através de obras e projetos, para sensibilizar de modo poético e crítico, político e criativo o público que visita o Festival, este ano como exposição online. ${ }^{4}$

A curadoria nesta edição é compartilhada entre esta autora (UFSM) e Mariela Yeregui (UNTREF) tem assistência da doutoranda Manoela Vares (UFRGS), graduandas Flávia Queiróz e Alice Siqueira (UFSM). Os artistas convidados para o Festival, tratam do tema água e sustentabilidade através de uma proposta poética e crítica, tanto mais literal e direta, quanto transversal e insinuada. As obras e projetos que integram o FACTORS 7.0, com os respectivos textos curatoriais, são apresentados neste artigo na mesma sequência da exibição online, mas de modo condensado. Para conhecer melhor artistas e obras, o Festival segue em toda a sua dinâmica de acontecimento online, no Instagram do LABART. 

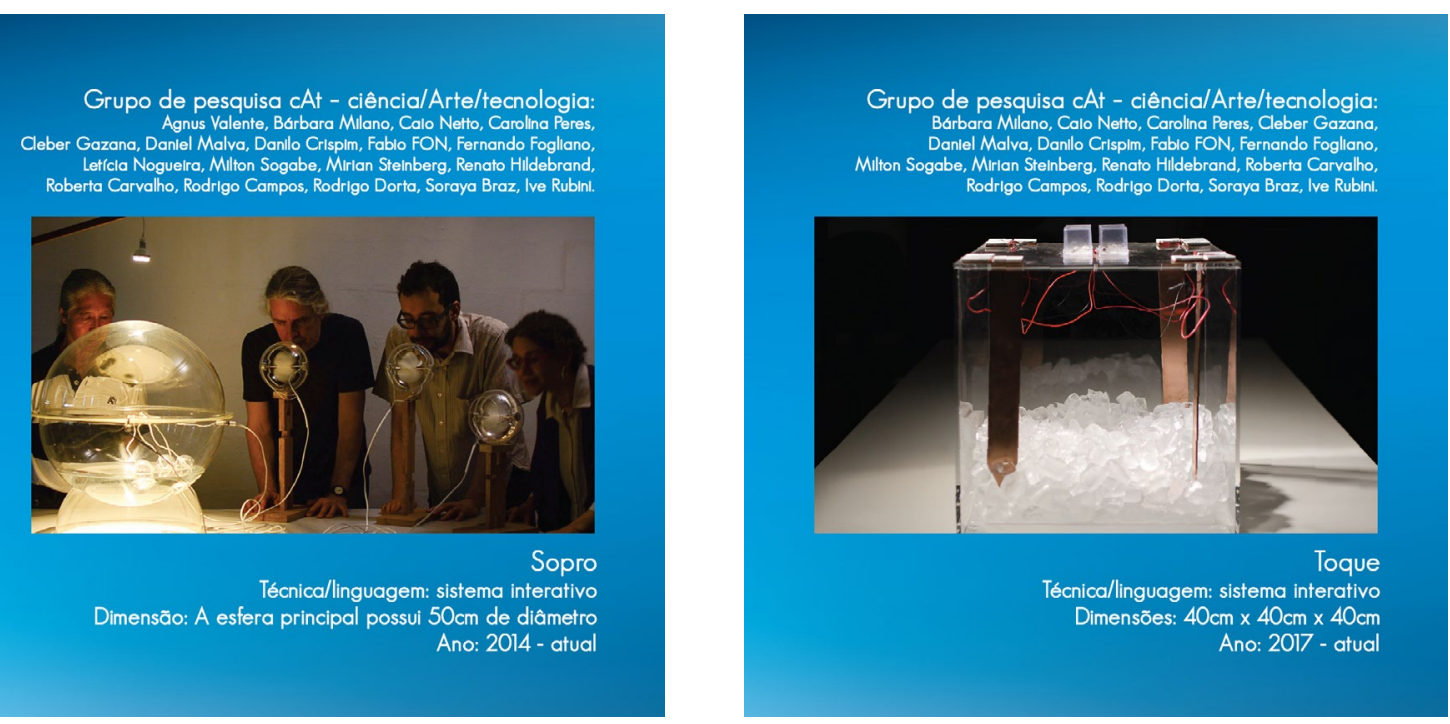

Figs $4 \mathrm{a}-4 \mathrm{~b}$. Post artista e obra do FACTORS 7.0 para Instagram Fonte LABART, 2020

Figs 5 - 6. Post artista e obra do FACTORS 7.0 para Instagram Fonte LABART, 2020
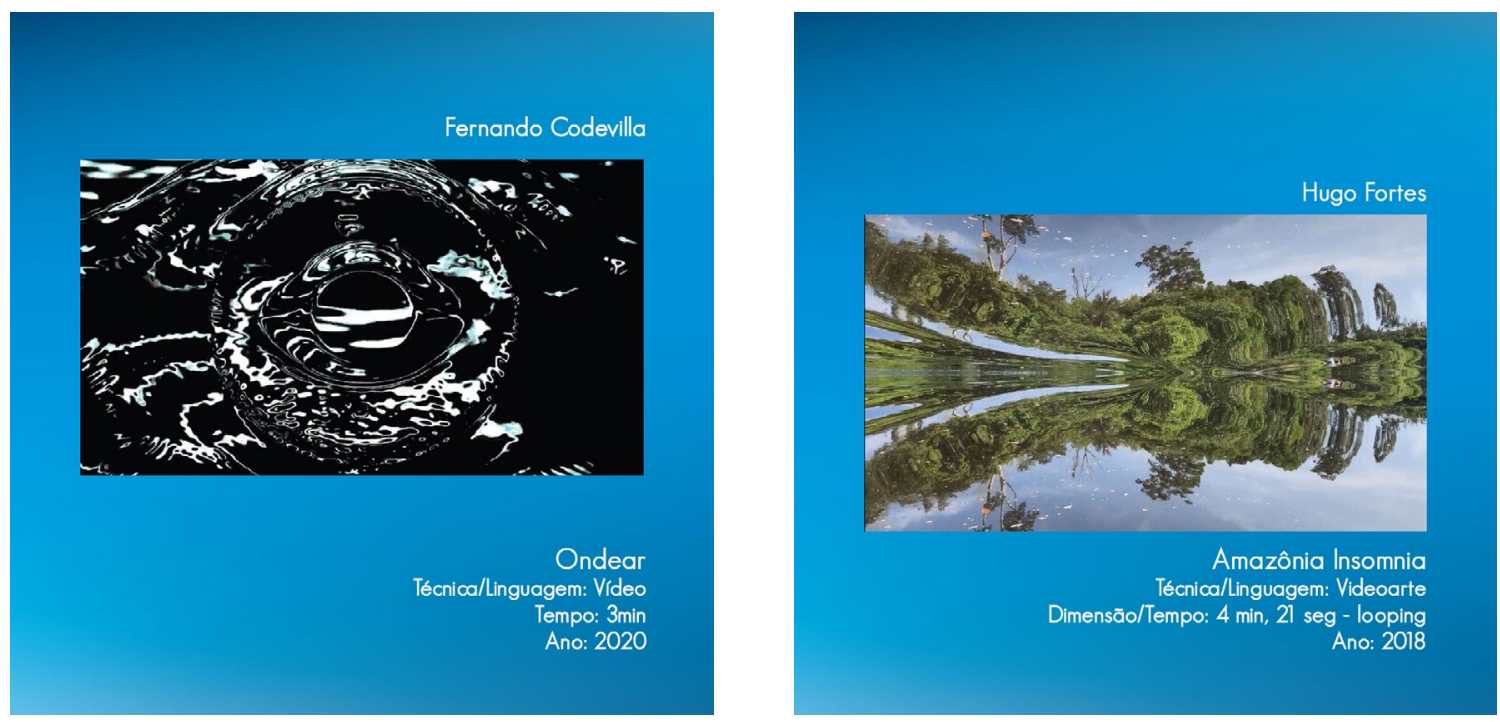

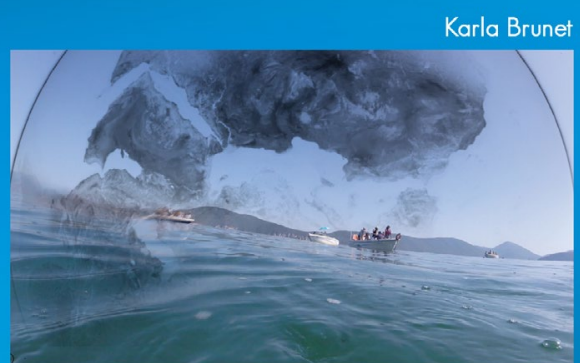

Fronteiras Fluidas Técnica/linguagem: vídeo arte

Dimensão/Tempo: $4 \mathrm{~min}$ Ano: 2020

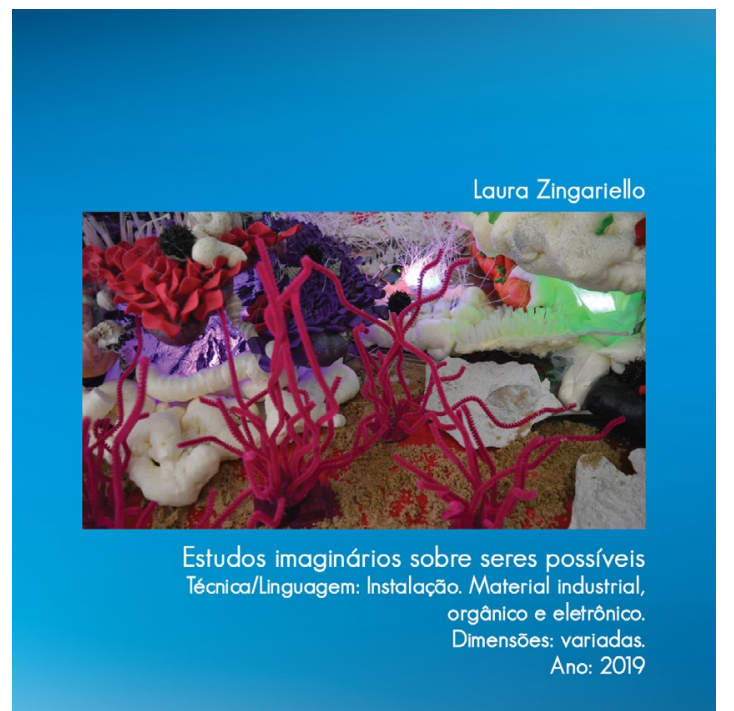

Figs 7 - 8. Post artista e obra do FACTORS 7.0 para Instagram Fonte LABART, 2020 
Fig 9. Post artista e obra do FACTORS 7.0 para Instagram Fonte LABART, 2020

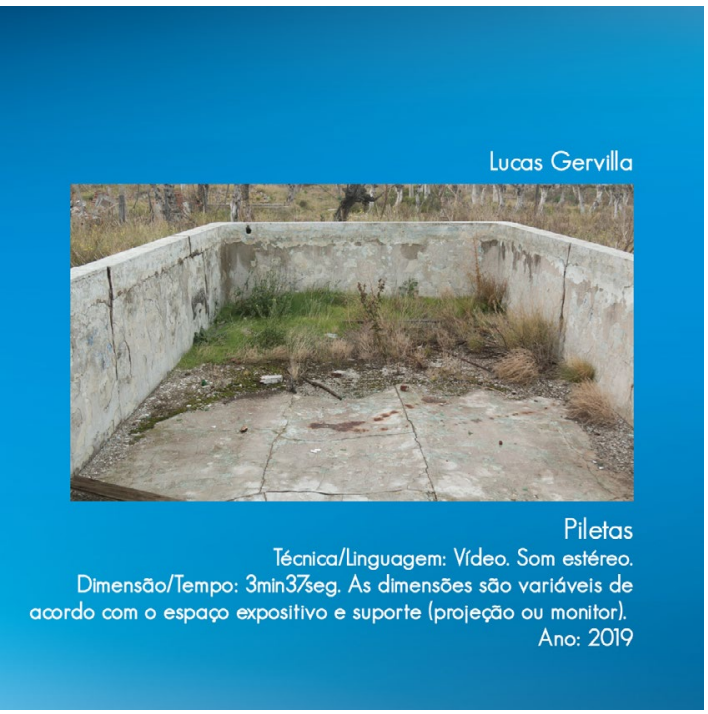

"Sopro" e "Toque" do Grupo cAt, Brasil (Fig 4 a b). Sopro e Toque configuram-se como objeto e instalação de um sistema poético interativo, em que a água, o elemento primordial da vida, revela, na transparência, a sutileza entre o som e o silêncio, o movimento e o repouso. As obras, seja para gerar energia por meio de tecnologias simples como cata-vento ou sensores táteis, seja para chamar atenção de fontes de energia limpa na interação com o público, discutem a sustentabilidade energética, também na Arte.

"Ondear" de Fernando Codevilla Brasil (Fig 5). A dinâmica repetida dos pingos de chuva define, na superfície da água, um ritmo visual e sonoro contrastante. De estranhamento, tanto pela coloração metálica que às vezes a imagem assume, quanto pelas ondas que parecem gerar energia acústica. De familiaridade, seja no som da chuva na água, ou no movimento concêntrico dos pingos. O vídeo explora com sensibilidade a fluidez de um fenômeno natural para propor padrões audiovisuais inusitados.

"Amazônia Insomnia" de Hugo Fortes, Brasil (Fig 6). 0 vídeo revela paisagens de efeitos quase caleidoscópicos, com rebatimentos, sobreposições, reflexos e transparências de imagens dos rios e da floresta amazônica. Neste cenário poético, a sonoridade suave, repetida e marcante, gera um convite à contemplação ativa de um imaginário. Tanto na intensidade do movimento espelhado das águas, quanto na pulsação de uma energia que emana das forças da natureza, evocando uma sensibilidade ancestral. Um convite à preservação das culturas nativas.

"Fronteiras Fluidas" de Karla Brunet, Brasil (Fig 7). A água, um mapa e três fronteiras definem a experiência da natação selvagem realizada no lago Prespa, encontro entre Grécia, Albânia e Macedônia do Norte. 0 vídeo revela imagens e sons que vão desde a paisagem real, explorada no movimento do nado e do mergulho, até imagens poéticas manipuladas para enfatizar a êxtase do encontro em um território fluido. A linguagem videográfica marca, no tempo, esse momento intimista das relações da artista e a natureza, do corpo e a água, como fronteiras líquidas.

"Estudos imaginários sobre seres possíveis" de Laura Zingariello, Argentina (Fig 8). A instalação define um espaço híbrido de componentes, orgânicos e inorgânicos, encontrados e recolhidos pela artista, para recriar um recife de corais. A obra traz uma crítica contundente à poluição nos oceanos, com materiais sintéticos para estruturar os corais embranquecidos, e dispositivos low tech para luz e movimento artificiais. Nessa interação entre os corais e meio ambiente da exposição, o público contempla a degradação de um ecossistema.

"Piletas" de Lucas Gervilla, Brasil (Fig 9). O vídeo traz uma série de intervenções sonoras nas piscinas de Epecuén, antes do rompimento de uma barragem e inundação da cidade. Em um lapso espaço-temporal, as "Piletas", vazias e silenciosas, são preenchidas por uma sonoridade contagiante que invade todo o lugar. Tanto o plano panorâmico da paisagem destruída, quanto os detalhes das piscinas abandonadas, são acompanhados no percurso impactado e crítico do olhar do artista. 


\section{Estratégia Expositiva Online}

Tanto a definição de "exposição espetáculo" apresentada por CHAUMIER (2012), quanto a "exposição como um meio de comunicação", defendida por BLANCO (2009) poderiam ser rediscutidas e ampliadas diante das plataformas usadas para as exposições online, nas redes sociais.

Uma das questões mais desafiadoras para a curadoria e expografia do Festival em 2020 foi a adaptação para a exibição online. Com a pandemia, procurou-se alguma estratégia expositiva que pudesse ao mesmo tempo ser viável e atrativa para atender às demandas de obras de Arte e Tecnologia. Não foi fácil, pois para a exposição, com argumento curatorial transdisciplinar e conceitos de água e sustentabilidade, haviam sido selecionados do ano anterior artistas, na sua maioria já confirmados, com obras previstas para o espaço físico. Deste modo, contatou-se cada artista para apresentar uma proposta de exposição como acontecimento online, para as redes sociais, partindo da plataforma do Instagram, Facebook e Youtube do LABART.

Diante da impossibilidade de uma mostra presencial, in loco, a curadoria precisou, junto com os artistas, encontrar soluções para exibição das obras. Por exemplo, entre os artistas, estavam aqueles do grupo cAt que já vinham trabalhando com o tema água e apresentaram a sua primeira experiência em uma proposta de objeto/sistema em 2017, no ISEA, na Colômbia. No FACTORS 7.0, apresentariam duas obras que exigiriam igualmente espaço físico, mas optou-se por exibir um vídeo documento. Alessandra Bochio e Felipe Castellani, performariam in loco, entre som e imagens, água e energia. Laura Zingariello faria com uma instalação denunciando a poluição nos oceanos, assim como Alejandra Isler, uma videoinstalação, a partir do deserto de sal, abordando a água em outra dinâmica, necessitaria do espaço físico. Já Hugo Fortes, que defendeu tese sobre a água na arte contemporânea, pode escolher, entre seus inúmeros trabalhos, um de videoarte na Amazônia. Camila Zappe exploraria, a partir da fotografia, a água em uma estética do confinamento, mas produziu também em videoarte, o que facilitou a exibição. Fernando Codevilla retomou a água do ponto de vista da sonoridade da chuva, já em produção audiovisual finalizada, assim como Lucas Gervilla, com a videoarte sobre o rastro de destruição de uma barragem rompida. O mesmo com Karla Brunet, cuja apresentação já seria em videoarte de sua experiência no mar da Macedônia. Portanto, do conjunto dos artistas, as obras do grupo cAt, da dupla Castellani e Bochio, e de Laura, foram apresentadas como vídeo documento no Festival, ou seja, registro das obras ou das ações. Os demais artistas exibem videoarte, de modo que o público teve acesso online à obra, ela mesma.

Neste ano, a obra do cAt, que era objeto/sistema interativo, também foi pensada com um princípio de interação em rede. 0 grupo propôs uma versão das obras em ambiente virtual simulando a interação. Esta proposta do cAt levanta uma questão necessária de ser estudada e projetada para o Festival, que não apenas realizar uma mostra online. Espera-se que na próxima exposição do FACTORS já exista um ambiente virtual para obras interativas, seja através do LABART ou do projeto Museu Arte-Ciência-Tecnologia/UFSM. 


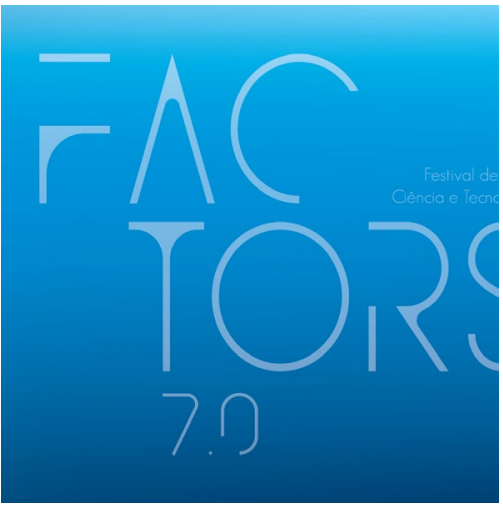

Imagem 9 - Post Curadoria/obra

Primeira parte da marca do FACTORS;

Variação tonal.

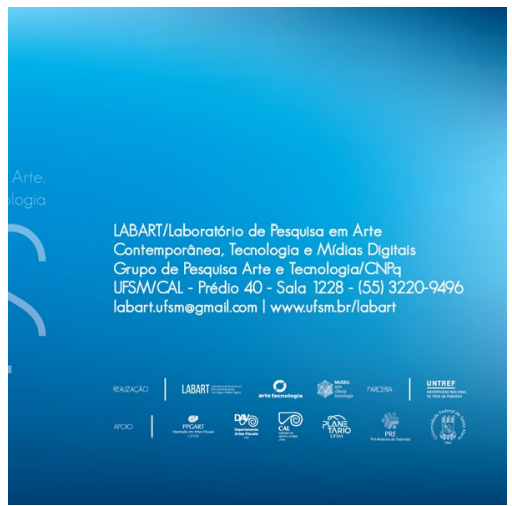

Quadro 1. Sequência de imagens da expografia do FACTORS 7.0 para Instagram

Fonte LABART, 2020
Imagem 10 - Post Curadoria/obra

Segunda parte da marca do FACTORS;

Informações institucionais de contato, realização, parceria e apoio.

\section{Dinâmica Online}

A abertura do Festival através do Google Meet e a transmissão via FAROL/UFSM foi determinante para impulsionar o acesso a mostra online a partir de 18 de agosto. Neste dia às 19:00, com a presença de autoridades, artistas, convidados e equipe do LABART no Meet, a abertura teve mais de 200 pessoas acompanhando o evento online no FAROL. A artista Alejandra Isler, cujas postagens são compartilhadas enquanto estratégias expositivas nesse artigo, abriu a exposição.

De 18 a 28 de agosto, a cada dia foi apresentado somente um artista e obra para valorizar a presença individual deles no espaço-tempo do Festival, como um acontecimento online. Para esta edição, entendeu-se que no ambiente das redes sociais do Instagram e Facebook, a postagem de todas as obras no dia da abertura da exposição não seria a mais adequada para o 
engajamento do público, considerando que não era apenas um post de uma imagem, mas de um conjunto de dados visuais, textuais e audiovisuais. Por outro lado, se as postagens de todas as obras fossem feitas de uma única vez, no caso de trinta no total, e não três por dia como realizado, poderiam ocasionar um overposting, ou seja, uma sobreposição das postagens nas atualizações do público, enquanto seguidor do Instagram.

Para exibição da mostra, portanto, utilizou-se a estratégia de três postagens diárias no Instagram8, para a mesma obra: uma da curadoria/ obra do FACTORS 7.0 em carrossel; outra intermediária de um vídeo-depoimento de 59 segundos de cada um dos artistas falando sobre seu processo e obra; e, uma terceira postagem da mediação, também em carrossel. Deste modo, na sequência das postagens manteve-se também uma espécie de expografia no Instagram do LABART, pois na medida em que o público acessasse o feed (Fig. 11) teria a ideia não só da continuidade, mas também de uma visualização geral da exposição na plataforma.

A proposta foi essa, mas não há como prever se o público, necessariamente, acessou o feed. Um público menos familiarizado pode ter seguido a exposição apenas pelas atualizações, o que é mais provável, e teve acesso às obras de modo aleatório, não na sequencia prevista no feed. Sobretudo, os seguidores que tem pouca interação com o perfil do LABART no Instagram. Talvez parte do público, sequer tenha tomado conhecimento da ideia de uma expografia pensada como um acontecimento online, também de permanência no feed. Um estudo já foi iniciado para melhor compreender e rever estas dinâmicas próprias de postagem e interação do público com o Instagram, em propostas futuras de expografias online. De qualquer modo, entende-se que esta primeira mostra online do FACTORS 7.0 foi exitosa. Tanto pela manutenção do evento em meio a pandemia, quanto pela interação do público, os inúmeros acessos e a visibilidade adquirida online.

Para o Festival, pensou-se em inserir todos os dados de uma exposição in loco nas postagens e, ao mesmo tempo, utilizar outras funcionalidades do Instagram, entendidas como estratégias disponíveis. Portanto, além das atualizações no feed já descritas, usou-se as legendas, os stories, os destaques e a biografia: Post da curadoria/obra; Post do vídeo-depoimento em $59^{\prime}$, tempo em que aparece integralmente no feed; Legenda curadoria FACTORS 7.0 Arte e Sustentabilidade, nome do artista, obra e link da obra, indicação das obras, uso de hashtags; Legenda post vídeo-depoimento artistas com biografia; Legenda MEDIAÇÃO FACTORS 7.0, ficha técnica, uso de hashtags; Stories de chamada da curadoria; Stories da mediação; Destaque MEDIAÇÃO no perfil, com os stories da mediação salvos, para acesso após as $24 \mathrm{~h}$ de sua duração; Biografia do perfil no Instagram, com links externos disponíveis para acesso direto ao vídeo da obra no Youtube; e, todos os vídeos das obras foram disponibilizados também no IGTV do Instagram para o público assistir sem sair da rede social.

Fig 11. Print parcial do Feed do FACTORS 7.0 no Instagram Fonte LABART, 2020 
Essa organização de postagens ${ }^{9}$ gerou no feed uma sequência visual, como um convite ao público, mantendo a ideia de início, meio e fim do Festival. De qualquer modo, apesar da exposição ter começado em 18 de agosto, com a primeira postagem diária de uma obra, e encerrado no dia 28 do mesmo mês, a exibição segue permanente no Instagram do LABART e pode ser acessada a qualquer tempo, como acontecimento online.

Acredita-se que a dinâmica das postagens, primeiro da curadoria/ obra, a segunda do vídeo-depoimento do artista e a terceira da mediação, somadas as demais funcionalidades do Instagram, gerou um conjunto de informações para aproximar o público de cada obra e proporcionar um entendimento da exposição. Esta mesma dinâmica possibilitou efetivamente o acesso a obra, no caso daquelas em videoarte, e o que se espera de uma exposição: proporcionar ao público uma experiência sensível, própria do campo da arte.

\section{Finalizando}

Em pleno 2020 a pandemia, iniciada em março e com previsão de fim em setembro, pode levar ainda dois anos para se estabilizar. Neste período, todos se adaptaram ou ainda estão se adaptando, não apenas em relação ao distanciamento físico, a manutenção das atividades acadêmicas e sociais através de diferentes plataformas, sempre em rede, mas também ao fato de continuar produzindo no meio universitário, mesmo em tempos tão raros. O FACTORS reinventa-se nas redes sociais, principalmente no Instagram, também da divulgação pelo Facebook, e no Youtube, para permitir o acesso à visualização das obras, em videoarte. Incluindo as três obras que se apresentam como vídeo-documento, pois não há possibilidade de acompanhar ao vivo a performance de Bochio e Castellani, nem de transitar em torno da instalação de Laura, menos ainda estabelecer qualquer interatividade com a proposta original, ainda que adaptada para o ambiente virtual, do grupo cAt. E sem dúvida, assistir as obras pelo IGTV do Instagram ou pelo Youtube, no celular ou no computador, não é o mesmo que visualizar grandes telas ou projeções, no espaço de uma sala de exposições.

Mesmo assim, o Festival assume sua sétima edição como um acontecimento online. Entre as estratégias expositivas, estão a expografia online para exibição das obras e a dinâmica online, com base no Instagram, Facebook e Youtube do LABART. Quanto a dinâmica para divulgação, o uso de redes sociais e suas linguagens próprias, promove não apenas o acesso as informações por distintas vias, mas proporciona a mobilização do público em torno da exposição, para proporcionar uma experiência sensível. 
No LABART, entre outras atividades, trabalha-se desde 2014 para o Festival in loco, que em 2020 se adapta a essa exposição online. A equipe, que é formada por artistas, designer gráficos, jornalistas, entre graduandos, mestrandos, doutorandos, pós-doutoranda das Artes Visuais, colaboradores e docentes da UFSM, tem 16 pessoas envolvidas, contando com essa autora, coordenadora do laboratório. Acredita-se que toda a equipe do LABART trabalhou unida em prol da exposição, apesar deste período complicado pelo qual se está passando, motivada em manter a continuidade do FACTORS, que aconteceu no final de agosto, como previsto. Também como uma maneira de resistência, neste momento difícil para o país.

O resultado alcançado neste ano é satisfatório, considerando as adversidades e o espaço-tempo para a realização da mostra. Durante e depois da exposição, algumas questões surgiram para avaliação e necessária atualização do Festival para as edições seguintes, que podem seguir in loco e/ ou online. Entre elas, está a ideia de projetar um ambiente virtual para proporcionar interação às obras de Arte Tecnologia, para o próximo FACTORS.

1 LABART - Laboratório de Pesquisa em Arte Contemporânea, Tecnologia e Mídias Digitais; CAL - Centro de Artes e Letras;

UFSM - Universidade Federal de Santa Maria. Integram o Laboratório estudantes de graduação em Artes Visuais, bolsistas de Iniciação Científica Fipe-UFSM, PROBIC-FAPERGS, PIBIC-CNPq; de pós-graduação, mestrandos e doutorandos em Artes Visuais PPGART/UFSM, bolsistas CAPES; docentes e colaboradores. https://www.ufsm.br/laboratorios/labart/

2 https://www.ufsm.br/editoras/editorappgart/

3 Instagram https://www.instagram.com/labart.ufsm - Facebook https://www.facebook.com/labart1228 -

Youtube https://www.Youtube.com/channel/UCw274rzHP9t7muJG9zAW_aw

4 Texto apresentado durante a abertura online do FACTORS 7.0 via Google Meet transmitido pelo Farol UFSM. https://farol.ufsm.br/

5 Contou com Ana Luiza Martins, Natasha Carvalho e esta autora para versão preliminar, ampliada em conjunto com Cristina Landerdahl, Raul Dotto na expografia online, e Fernando Codevilla da organização do FACTORS.

6 Projeto Gráfico, Eduardo Della Flora.

7 Mediação, Daniel Lopez, Flávia Queiróz, Hosana Celeste, Rittieli Quaiatto.

8 Social Media, Natascha Carvalho.

9 No Instagram, o Festival atingiu um público amplo a cada dia. Considerando as três postagens feitas no feed referente a cada obra (curadoria/obra, vídeo-depoimento artista e mediação), as que tiveram mais acessos durante o período da exposição foram: Curadoria/obra "Fronteiras fluidas", de Karla Brunet; vídeo-depoimento de Alessandra Bochio e Felipe Castellani; e a mediação da dupla Bochio e Castellani. Este fato pode ter derivado de algumas variáveis, como compartilhamentos externos feitos pelos próprios artistas, horários e dias específicos de acesso, entre outros. A agenda de postagem de uma obra por dia teve como horários previstos: 19:00 (dia principal) Post Curadoria Feed; 19:30 - Post Vídeo Artista; 20:00 - Post Mediação; 20:01 em diante - Stories Mediação + Stories compartilhando ou post curadoria ou post mediação; $11 \mathrm{~h}$ às $14 \mathrm{~h}$ (dia seguinte) - Stories com um trecho do vídeo da obra do dia anterior convidando o público para vê-la na íntegra no Youtube. 


\section{Referências}

BLANCO, Ángela García. La Exposición Un medio de comunicación. Madrid: Akal, 2009.

CHAUMIER, Serge. Traité d'expologie Les écritures de l'exposition. Paris: La documentation Française, 2012.

PAUL, Christiane. New Media in the White Cube and Beyond. Curatorial models for digital arts. Los Angeles: University of California Press, 2008.

SANTOS, Nara Cristina. Art-Science-Technology: Curatorial Strategies in FACTORS. ARTECH 2019, p. 241-246. Digital Media Art Ecosystems. Proceedings of the 9th International Conference on Digital and Interactive Arts. Org. Universidade Católica Portuguesa, Braga, 2019. SMITH, Terry. Talking Contemporary Curating. New York: ICI, 2015.

ZIZEK, Slavoj. Acontecimento. Uma viagem filosófica através de um conceito. Rio de Janeiro: Zahar: 2017. 